\title{
Diurnal variation of NMR based blood metabolites in calves fed a high plane of milk replacer: a pilot study
}

\author{
Morteza H. Ghaffari ${ }^{1}$, Jayden A. R. MacPherson ${ }^{1}$, Harma Berends ${ }^{2}$ and Michael A. Steele ${ }^{1 *}$
}

\begin{abstract}
Background: Blood profiles have been used to monitor herd health status, diagnose disorders, and predict the risk of diseases in cattle and calves. Characterizing plasma metabolites in dairy calves could provide further insight into daily metabolic variations and the mechanisms that lead to metabolic diseases. In addition, by understanding physiological ranges of plasma metabolites relative to meal and the time of feeding in healthy animals, veterinarians can accurately diagnose abnormalities with a blood test. For diagnostic purposes, nuclear magnetic resonance (NMR) spectroscopy shows promise as a new and reliable method to determine a large number of blood metabolites simultaneously.

Results: Results demonstrated that the concentration of specific metabolites in plasma (i.e., lysine, isoleucine, leucine, tyrosine, glutamine, creatine, and 1-methylhistidine) fluctuated around meal times, while others (i.e., glutamic acid, methanol, formic acid, and acetic acid) maintained a stable temporal concentration. In addition to temporal changes in concentration, results also characterized differences for overall plasma metabolite concentrations; for example, methionine had the lowest (38 $\mu \mathrm{M})$ while glutamine had the highest concentration $(239 \mu \mathrm{M})$ amongst plasma AA. This is the first report describing how the plasma metabolome changes during 24-h period in young calves fed an elevated plane of milk replacer twice daily.

Conclusions: Data from this pilot study will help to establish reference standards for future metabolic diagnostics in dairy calves. In addition, this pilot study illustrated that feeding milk replacer may influence plasma metabolite concentrations. With the rapid implementation of blood metabolomics in monitoring animal health, it is then important to consider the time of feeding during the day when interpreting metabolomics analysis results.
\end{abstract}

Keywords: Calf, Plasma, Metabolomics, NMR spectroscopy

\section{Background}

Plasma metabolites are widely used to monitor the health and metabolic status of cattle herds [1]. Nuclear magnetic resonance (NMR) spectroscopy is a method that can be applied to identify and quantify many metabolites in biological samples, including blood. The minimal sample preparation and high analytical reproducibility along with the non-destructive characteristics of NMR spectroscopy represents significant advantages for employing NMR in the field of metabolomics research compared with other methods

\footnotetext{
*Correspondence: masteele@ualberta.ca

'Department of Agricultural, Food, and Nutritional Science, University of

Alberta, Edmonton T6G 2P5, Canada

Full list of author information is available at the end of the article
}

[2]. Identification of metabolomic profiles using NMR that relate to specific outcomes such as metabolic disorders and diseases could improve the speed of diagnosis and treatments [3]. Reported metabolite research values vary in sampling times during the day as well as the physiological stage of the animal. This represents a serious knowledge gap for veterinary diagnostics as the plasma concentrations of some metabolites, such as non-esterified fatty acids, glucose, and amino acids (AA), have been shown to be affected by time of feeding in cattle $[4,5]$. This is important to consider for clinical investigations to avoid misinterpretation of results due to the meal effects. 
Blood metabolite concentrations may also fluctuate throughout the day, therefore sampling time differences between studies may be a primary reason for the discrepancies in published literature. Having temporal reference data for metabolite concentrations of dairy calves could further strengthen our understanding of physiologically healthy concentrations versus metabolic disorders (i. e., chronic diarrhea, pneumonia, and insulin sensitivity). Moreover, most of the currently available data describing metabolic responses comes from studies in adult cattle, and these findings may not represent metabolomic profiles of calves. Therefore, it is important to understand and characterize the metabolome of calves to establish physiologically healthy fluctuations in metabolites throughout the day.

In dairy calves, it has been shown that increasing meal size results in slower gastric emptying [6]. The rate at which nutrients empty from the abomasum can also influence the rate at which those nutrients are delivered to the small intestine and absorbed into the bloodstream [7]. Therefore, the objective of this report is to describe diurnal variations of plasma metabolites in dairy calves fed an elevated plane of milk replacer twice daily using NMR spectroscopy. In this pilot study, NMR-based metabolomic analysis technology was used because it allowed us to study a large number of metabolites in the blood of dairy calves. To the best of our knowledge, this is the first time that a 24-h period of plasma metabolome has been characterized by NMR spectroscopy in calves fed an elevated plane of nutrition.

\section{Results}

All calves were clinically healthy at time of sampling. The mean daily starter feed intake and milk replacer intake from day 19 to day 23 of age were $46.0 \pm 21.4 \mathrm{~g} /$ day and $7.51 \pm 0.49 \mathrm{~L} /$ day, respectively.

\section{Nuclear magnetic resonance spectroscopy}

Twenty-four hour mean values of the plasma essential amino acids (EAA; histidine, lysine, methionine, phenylalanine, valine, leucine, and isoleucine) and nonessential amino acids (NEAA; alanine, glutamine, glutamic acid, glycine, proline, and tyrosine) are presented in Fig. 1a. Glutamine had the highest concentration $(238.6 \mu \mathrm{M})$ while methionine was the lowest $(38 \mu \mathrm{M})$ amongst plasma AA. Valine and lysine were the most abundant essential plasma AA. Mean baseline and four-hour postprandial plasma concentrations of AA are presented in Fig. 1b. A four-hour postprandial sampling time was selected based on the knowledge that the soluble components of milk enter the small intestine within 2 to $3 \mathrm{~h}$ after a meal [8]. In the morning meal, the 4-h postprandial plasma concentrations of histidine, lysine, leucine, isoleucine, valine, methionine, phenylalanine, alanine, proline, tyrosine, and glutamine were significantly higher $(P<0.05)$ compared with baseline. In the evening meal, the 4-h postprandial plasma concentrations of isoleucine, lysine, tyrosine, and glutamine were significantly higher $(P<0.05)$, and valine $(P=0.07)$ and alanine $(P=0.08)$ tended to be higher compared with baseline. The plasma concentrations of glutamic acid and glycine did not significantly change in response to time of meal feeding. The patterns of diurnal variation of plasma EAA and NEAA are displayed in supplementary file (Additional files 1 and 2).

The plasma AA concentrations varied markedly according to the time of day. Twenty-four-hour mean plasma glucose, glycerol, citric acid, and lactic acid concentrations are shown in Fig. 2a. Mean baseline and 4-h postprandial plasma recordings of glucose, glycerol, citric acid, and lactic acid concentrations are shown in Fig. 2b. Twenty-four hour mean concentrations of other plasma metabolites such as creatine, betaine, acetic acid, formic acid, dimethyl sulfone, 1methylhistidine, 3-hydroxybutyric acid, methanol, pyruvic acid, scyllitol, ethanol, and creatinine are presented in Fig. 3a and b. Mean baseline and 4-h postprandial plasma recordings of other metabolite concentrations are presented in Fig. $3 \mathrm{c}$ and $\mathrm{d}$.

The 4-h postprandial plasma concentrations of betaine (in the morning meal) and citric acid (in the evening meal) were significantly higher $(P<0.05)$ compared to their baseline. Plasma concentration of glucose tended to be higher $(P=0.10)$ at 4 -h postprandial compared to baseline after both meal feedings. Comparison of postprandial plasma concentrations of 1 -methylhistidine $(P<0.05)$ and creatine $(P<0.01)$ after both meal feedings revealed significantly higher concentrations at 4-h postprandial compared to their baseline. The patterns of diurnal variation of other plasma metabolites are displayed in an additional file (Additional file 3). Plasma concentration of creatine significantly increased after feeding to reach a maximum level of $222.3 \mu \mathrm{M}$ in less than $3 \mathrm{~h}$, followed by a progressive decrease until the next feeding. After the morning feeding, the plasma glycerol concentration numerically increased and there were small fluctuations throughout the day. Plasma concentration of pyruvic acid numerically increased after the morning meal, but its concentration significantly decreased after the evening meal. The plasma concentrations of other metabolites such as acetic acid, formic acid, 1-methylhistidine, dimethyl sulfone, 3-hydroxybutyrate, methanol, scyllitol, ethanol, and creatinine did not significantly change in response to time of meal feeding. 


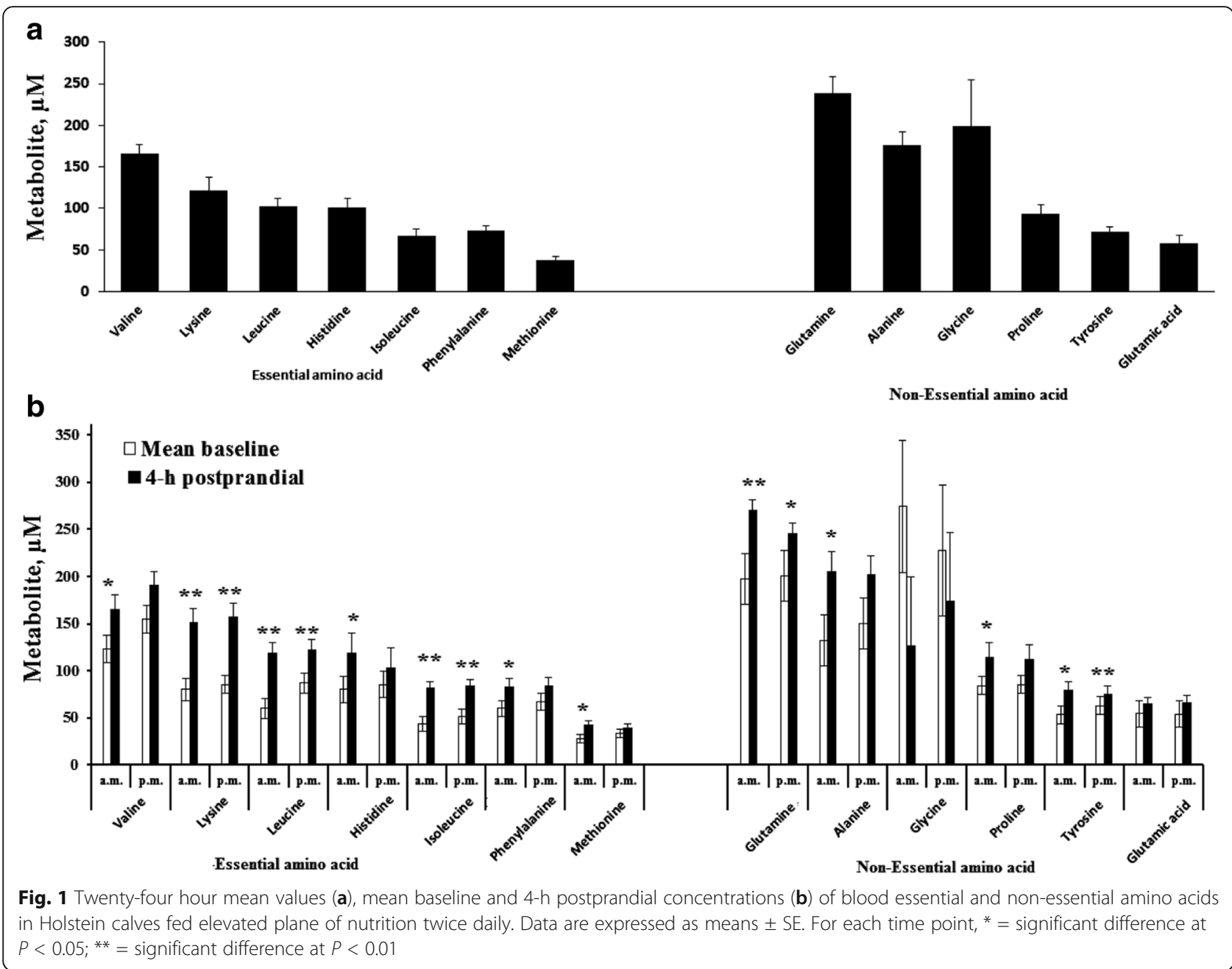

\section{Discussion}

Metabolomics is becoming an important tool in clinical research, allowing for very early and accurate diagnosis of disorders and diseases [9]; however, this technique is not implemented on most of dairy farms as a tool to selectively tailor management decisions in calves and cattle. The plasma metabolite profiles in dairy calves have not been properly characterized. Thus, this pilot study specifically focused on measuring the postprandial and diurnal variation of blood metabolites using NMR in three male Holstein dairy calves fed an elevated plane of milk replacer twice daily.

\section{Amino acids}

For dairy calves, milk provides most of the nutrients, such as the AA, needed to support adequate growth for young calves before they are able to digest solid feeds [10]. The postprandial concentrations of all EAA and some NEAA in the plasma significantly increased after ingestion of milk replacer in this pilot study. The observed difference in the plasma level of EAA after milk feeding is in agreement with previously reported data, indicating that the plasma EAA concentrations increased following milk feeding in pre-weaned calves [11]. In this study, the different postprandial concentrations of plasma AA and the degree of increase after the meal can partially be explained by different AA digestibility [12]. Plasma glutamine levels increased after MR feeding in this pilot study, which is consistent with the results of McCormick and Webb [13] who reported that glutamine was the only amino acid increased after feeding in plasma of calves. In contrast, Hammon and Blum [10] reported no change in the plasma glutamine concentration in calves fed only milk replacer during the first week of life. Glutamine was the most abundant free AA in calf plasma, which is consistent with previous findings underlining the important role of glutamine in maintaining net protein synthesis and accretion [14]. Studies on dietary glutamine utilization in human indicated at least $50 \%$ of the dietary glutamate and glutamine is taken up by the GIT and is completely oxidized to $\mathrm{CO}_{2}$ [15]. This means that the plasma 


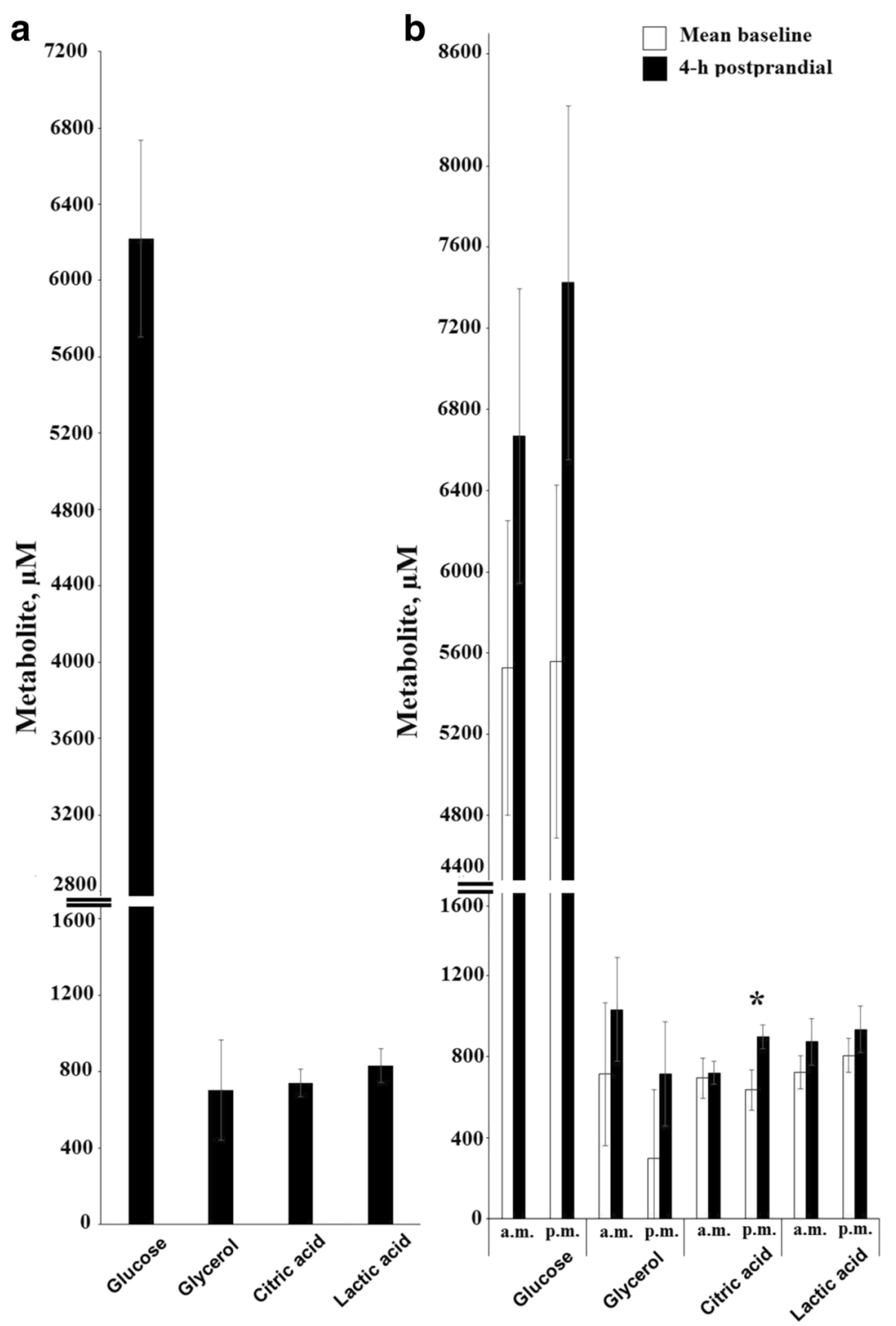

Fig. 2 Twenty-four hour mean values (a), mean baseline and 4-h postprandial concentrations (b) of blood glucose, glycerol, citric acid, and lactic acid in Holstein calves fed elevated plane of nutrition twice daily. Data are expressed as means \pm SE. For each time point, ${ }^{*}=$ significant difference at $P<0.05$

glutamine concentration of calves in this study may be affected by the utilization and metabolism of glutamine by small-intestine.

In contrast to all other post-prandial results, the plasma concentration of glycine was numerically lower than the baseline level $4 \mathrm{~h}$ after the meal. Glycine is synthesized in the body through various complex pathways involving serine, threonine, choline, and hydroxyproline via inter-organ metabolism involving primarily the liver and kidneys [16]. The lower postprandial glycine concentration in plasma of dairy calves might be associated with low concentration of glycine in milk $[17,18]$. Wang et al. [16] reported that the intake of glycine from milk provides at most only $20 \%$ of the glycine required by the 7-day old piglet; thus, $80 \%$ of the glycine needed by the piglets must be provided through endogenous synthesis.

The plasma AA concentrations in dairy calves are likely more affected by diets than mature cows. Halfpenny et al. [19] reported that plasma AA concentrations in dairy cows are relatively constant during the day. In addition, Huntington [20] showed that AA absorption in lactating cows was relatively constant until $12 \mathrm{~h}$ after feeding, likely because of the continuous outflow of microbial and dietary protein from the rumen, which is a key difference between pre-weaned calves and more mature weaned animals. Therefore, the results of this study indicated that the plasma AA status of young calves is highly related to milk replacer intake. 

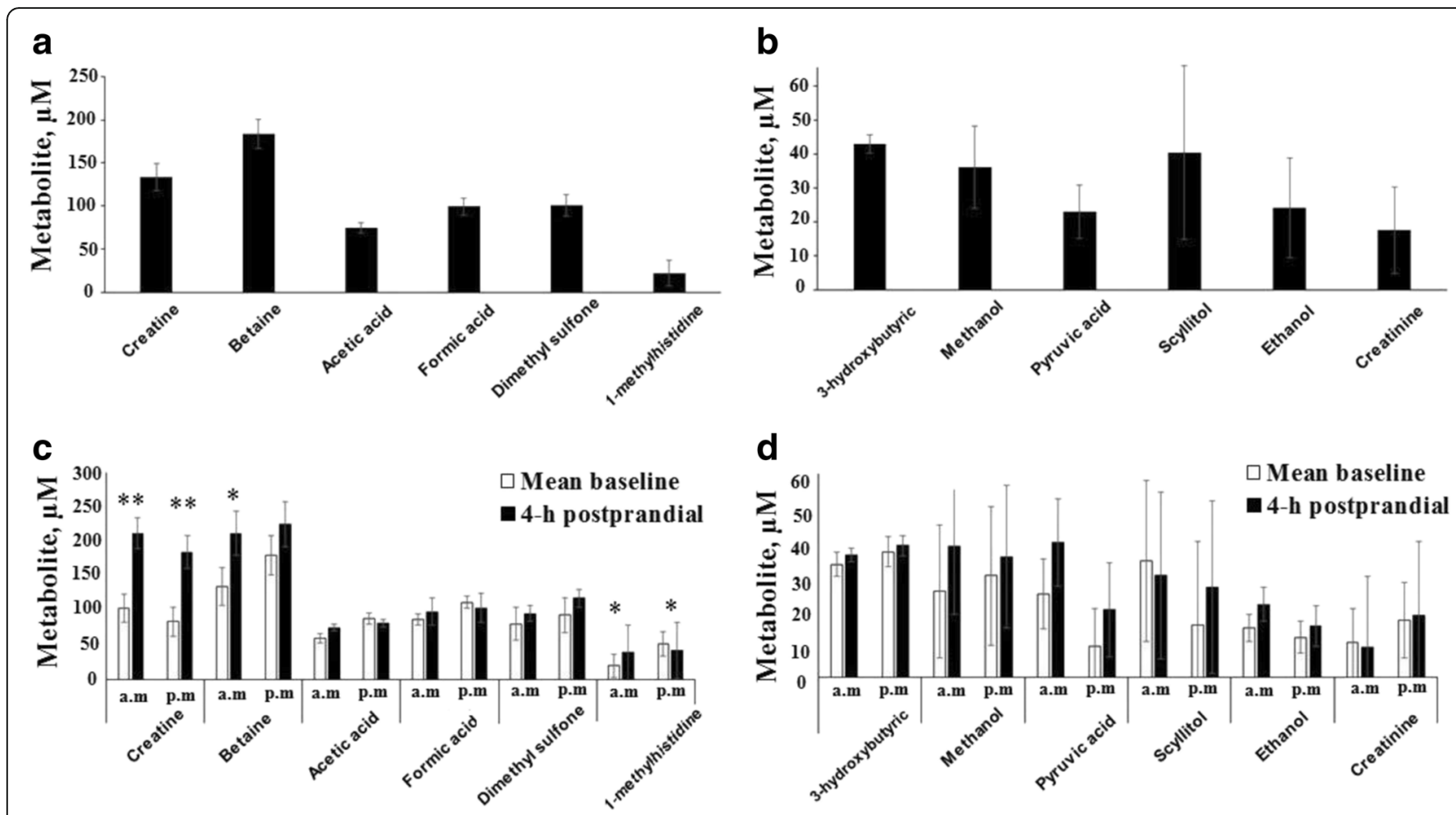

Fig. 3 Twenty-four hour mean values (a, b) and mean baseline and 4-h postprandial concentrations (c, $\mathbf{d}$ ) of blood metabolites in Holstein calves fed elevated plane of nutrition twice daily. Data are expressed as means \pm SE. For each time point, ${ }^{*}=$ significant difference at $P<0.05 ;{ }^{*}=$ significant difference at $P<0.01$

\section{Additional metabolites}

Glucose, lactic acid, citric acid, and glycerol were the most abundant metabolites in the plasma of the dairy calves in this report. The concentration of glucose in the calves in this study were within the range suggested for plasma glucose concentrations in dairy calves fed high plane of milk replacer at 4 week of age, which vary between 6500 and $8000 \mu \mathrm{M} / \mathrm{L}$ [6]. The postprandial concentrations of glucose in the plasma tended to increase after ingestion of milk replacer in this pilot study, which is in line with the results of previous studies [6, 21]. Plasma glucose concentration can be affected by the level of milk feeding, milk carbohydrate sources [22], endogenous glucose production from gluconeogenesis in the liver [23], and age [24]. As calves age, the concentration of plasma glucose decreases, which is mainly due to a shift in the primary source of energy from glucose to volatile fatty acid [25]. Therefore, milk feeding can be considered an important factor for influencing the postprandial plasma glucose concentration in dairy calves and should be considered when evaluating glucose concentrations in calves.

Lactic acid was the most abundant organic acid in the plasma of these calves. A post-prandial rise of lactate concentrations in the plasma has been previously reported in milk-fed calves [26, 27], although in this pilot study the rise was not significant in the calves. The accumulation of lactic acid is an important contributory factor to metabolic acidosis in neonatal calves with diarrhea in the previous study [28]. So far, limited information is available regarding the plasma concentration of citric acid in dairy calves. Citric acid is formed from acetyl-CoA and oxaloacetic acid in a reaction catalyzed by citrate synthase [29]. In this study, the plasma citric acid level increased after the evening meal. Reasons for the increased plasma level of citric acid following evening milk feeding in calves are unclear.

In this pilot study, plasma concentrations of creatine, betaine, and 1-methylhistidine were affected by time of meal feeding in calves. The plasma creatine concentrations were found to increase after each meal. Creatine is a nitrogenous amine found in muscle tissue that is involved in ATP synthesis and muscle function [30]. The elevation of the plasma creatine concentrations following the consumption of a milk replacer meal can be mainly due to the breakdown of proteins supplied by the milk replacer. Based on NMR spectroscopy, Basoglu et al. [3] reported that the concentration of plasma creatine increased in neonatal calves with diarrhea compared with healthy calves because of enhanced intestinal barrier function. The postprandial concentration of betaine in the plasma was also found to increase after the morning meal in this pilot study. Plasma betaine concentration in human beings can be affected by absorption from the intestine, synthesis from choline, metabolism to dimethylglycine, storage in muscle, liver and kidney tissues, as well as urinary elimination [31]. 
However, the factors causing the postprandial level of betaine rise in plasma are unclear. Plasma concentration of 1-methylhistidine observed in dairy calves also increased and was four times higher than those in a mature cow [32]. However, in this study, the postprandial increase of 1-methylhistidine may have been a consequence of increased breakdown of milk proteins. Therefore, it can be concluded that the diurnal variations of some plasma metabolites (i.e., acetic acid, formic acid, ethanol, and creatinine) were independent of meal feeding whereas the diurnal variations in most AA, creatine, 1-methylhistidine in plasma were strongly affected by meal feeding in calves.

\section{Limitations}

This study was a preliminary investigation of the diurnal variation of blood metabolites in 20 day old calves fed milk replacer. The major limitation of this pilot study was biological replication, and the findings could be very specific to this age group and this feeding regimen. However, this pilot study will provide the groundwork for further studies investigating post-prandial responses of blood metabolites in calf feeding programs.

\section{Conclusion}

Metabolomic profiling is an emerging diagnostic tool based on the comprehensive determination of many metabolites contained in bio-fluids and in biological samples. This pilot study indicated that some plasma metabolites exhibit a definite pattern and change with time relative to milk replacer feeding. These findings will be useful in guiding the design and interpretation of future metabolite-based studies in calves. Future metabolomics studies with larger sample sizes and different ages are required to verify the findings of this pilot study, and to explore its clinical application for the diagnosis and treatment of diseased animals.

\section{Methods}

This pilot study was conducted at the Trouw Nutrition Ruminant Research Centre (Boxmeer, The Netherlands). All procedures and sampling were approved by the Animal Care and Use Committee of Utrecht University (2014.III.04.045). Three Holstein bull calves (average age $20.0 \pm 1.0$ days) weighing $56.0 \pm 3.3 \mathrm{~kg}$ were housed in individual hutches $(1.07 \times 1.60 \mathrm{~m})$ bedded with wheat straw. All calves received reheated dam colostrum from a bottle (4 $\mathrm{L}$ divided into two feedings at 1 and $6 \mathrm{~h}$ of birth). All calves were fed milk replacer ( $150 \mathrm{~g} / \mathrm{L} ; 24 \%$ crude protein (skimmed milk powder), $18 \%$ crude fat, and $45 \%$ lactose; $\% 1.83$ lysine, \%0.55 methionine, and \%0.83 cystine + methionine, Sloten B.V. Deventer, The Netherlands) from nipple buckets. Calves were stepped up to $8 \mathrm{~L} /$ day of milk replacer during the first week of life which consisted of a total of $2.5 \mathrm{~L}$ for day 2 and 3, 3.0 L for day 4 and 5, and $3.5 \mathrm{~L}$ for day 6 and 7. From day 8 onward calves were fed a high plane of nutrition of $8 \mathrm{~L} /$ day which was divided equally and offered in two daily feedings $(07: 00 \mathrm{~h}$ and 17:00 h). Calves had ad libitum access to water, pelleted calf starter (18.2\% crude protein, $11.2 \%$ crude fibre, $2.2 \%$ crude fat, $3 \mathrm{~mm}$ pellet; AgruniekRijnvallei, Wageningen, The Netherlands), and wheat straw (3 $\mathrm{cm}$ chop length), provided in buckets in the front of the hutch. Jugular catheters (Intraflon 2 13G, Ecouen, France) were inserted in the morning $(08: 00 \mathrm{am})$ of the sampling day. Starting at 12:00 $\mathrm{pm}$, blood samples were collected every hour for $24 \mathrm{~h}$ via the jugular catheters in EDTA $(10 \mathrm{ml})$ vacutainers. Immediately after each collection, all catheters were flushed with a $2 \%$ heparinized saline solution. Blood samples were immediately centrifuged at $2772 \times g$ for $30 \mathrm{~min}$, after which the plasma was separated, frozen at $-20{ }^{\circ} \mathrm{C}$ and shipped on dry ice to The Metabolomics Innovation Centre at the University of Alberta, Canada for NMR spectrum analysis. The NMR samples were prepared as described by Psychogios et al. [33]. All ${ }^{1} \mathrm{H}-\mathrm{NMR}$ spectra of blood samples were collected on a $500 \mathrm{MHz}$ (Varian Inc., Palo Alto, CA, USA) spectrometer equipped with either a Z-gradient PFG Varian cold-probe or a $5 \mathrm{~mm}$ $\mathrm{HCN}$ Z-gradient pulsed-field gradient (PFG) roomtemperature probe. The resulting ${ }^{1} \mathrm{H}-\mathrm{NMR}$ spectra were processed and analyzed using the Chenomx NMR Suite Professional software package version 6.0 (Chenomx Inc., Edmonton, $\mathrm{AB}$, Canada), as previously described [34].

\section{Statistical analysis}

Data of the plasma metabolome are presented as means \pm standard error of the mean, obtained using PROC MEANS of SAS [35]. T-tests were used to determine the significance of changes between baseline and four-hour postprandial. The mean baseline is the average of the metabolite concentration $2 \mathrm{~h}$ before the meal (at 7:00 $\mathrm{h}$ and 17:00 h).

\section{Additional files}

Additional file 1: Concentrations of blood essential amino acids measured at hourly interval for $24 \mathrm{~h}$ from 05:00 to 04:00 h. Feeding times are marked with an arrow. Data are expressed as means \pm SE. (DOC $426 \mathrm{~kb}$ )

Additional file 2: Concentrations of blood non-essential amino acids measured at hourly interval for $24 \mathrm{~h}$ from 05:00 to 04:00 h. Feeding times are marked with an arrow. Data are expressed as means \pm SE. (DOC $189 \mathrm{~kb}$ )

Additional file 3: Concentrations of blood metabolites with response to meal feeding times of 7:00 and 17:00 measured at hourly interval for $24 \mathrm{~h}$. Feeding times are marked with an arrow. Data are expressed as means \pm SE. (DOC $724 \mathrm{~kb}$ ) 


\section{Abbreviations}

AA: Amino acids; BW: Body weight; EAA: Essential amino acids; GIT: Gastrointestinal tract; NEAA: Nonessential amino acids; NMR: Nuclear magnetic resonance; TCA: Tricarboxylic acid

\section{Acknowledgements}

The support of staff at the Trouw Nutrition Ruminant Research Center (Boxmeer, The Netherlands) is greatly appreciated.

\section{Funding}

Research reported in this publication was supported by funding provided Trouw Nutrition (Boxmeer, the Netherlands), Alberta Milk (Edmonton, AB, Canada) and The Natural Sciences and Engineering Research Council of Canada (438351).

\section{Availability of data and materials}

Not applicable.

\section{Authors' contributions}

MHG was a major contributor in analysing the data and writing the manuscript JARM conducted research, compiled data, and participated in drafting the manuscript. HB was involved in conducting research and reviewed the manuscript. MAS directed the research, reviewed the data and manuscript, and directed revisions. All authors have read and approved the manuscript.

\section{Ethics approval and consent to participate}

All procedures and sampling were approved by the Dutch Law on Experimenta Animals and the ETS123 (Council of Europe 1985 and the 86/609/EEC Directive).

\section{Consent for publication}

Not applicable.

\section{Competing interests}

The authors declare that they have no competing interests.

\section{Publisher's Note}

Springer Nature remains neutral with regard to jurisdictional claims in published maps and institutional affiliations.

\section{Author details}

'Department of Agricultural, Food, and Nutritional Science, University of Alberta, Edmonton T6G 2P5, Canada. ${ }^{2}$ Trouw Nutrition R\&D, P.O. Box 220, 5830 AE Boxmeer, The Netherlands.

Received: 2 January 2017 Accepted: 10 August 2017

Published online: 23 August 2017

References

1. Sun LW, Zhang HY, Wu L, Shu S, Xia C, Xu C, Zheng JS. 1H-Nuclear magnetic resonance-based plasma metabolic profiling of dairy cows with clinical and subclinical ketosis. J Dairy Sci. 2014;97:1552-62. http://dx.doi.org/10.3168/jds.2013-6757

2. Emwas AH. The strengths and weaknesses of NMR spectroscopy and mass spectrometry with particular focus on metabolomics research. Methods $\mathrm{Mol}$ Biol. 2015;1277:161-93. doi:10.1007/978-1-4939-2377-9-13.

3. Basoglu A, Baspinar N, Tenori L, Hu X, Yildiz R. NMR based metabolomics evaluation in neonatal calves with acute diarrhea and suspected sepsis: a new approach for biomarker/S. Metabolomics. 2014;4:134. http://dx.doi.org/ 10.4172/2153-0769.1000134

4. Ndibualonji BB, Dehareng D, Beckers F, Van Eenaeme C, Godeau JM Continuous profiles and within-day variations of metabolites and hormones in cows fed diets varying in alimentary supplies before short-term feed deprivation. J Anim Sci. 1997;75:3262-77. doi:10.2527/ 1997.75123262x.

5. Vacher PY, Schmitz M, Hirni H, Blum JW. Postprandial plasma variations of 3-methylhistidine compared to those of lysine, homoarginine and xylose on the normal conditions and in malabsorption in the suckling calf. Reprod Nutr Dev. 1990;30:471-82.

6. MacPherson JAR, Berends H, Leal LN, Cant JP, Martín-Tereso J, Steele MA Effect of plane of milk replacer intake and age on glucose and insulin kinetics and abomasal emptying in female Holstein Friesian dairy calves fed twice daily. J Dairy Sci. 2016: 99:8007-17. doi:10.3168/jds.2015-10826.

7. Bell FR, McLeay LM. The effect of duodenal infusion of milk, casein, lactose and fat on gastric emptying and acid secretion in the milk-fed calf. J Physiol. 1978;282:51-7

8. Drackley JK. Calf nutrition from birth to breeding. Vet Clin Food Anim. 2008; 24:55-86. doi:10.1016/j.cvfa.2008.01.001.

9. Zhang A, Sun H, Yan G, Wang P, Wang X. Metabolomics for biomarker discovery: moving to the clinic. BioMed Res Inter. 2015;1-6. http://dx. doi.org/10.1155/2015/354671

10. Hammon HM, Blum JW. Free amino acids in plasma of neonatal calves are influenced by feeding colostrum for different durations or by feeding only milk replacer. J Anim Physiol Anim Nutr. 1999;82:193-204. doi:10.1046/j.1439-0396.1999.00229.x.

11. Blum JW, Hammon H. Endocrine and metabolic aspects in milk-fed calves. Domest Anim Endocrinol. 1999;17:219-30. http://dx.doi.org/10. 1016/S0739-7240(99)00039-9

12. Li H, Diao YQ, Zhang NF, Fan ZY. Growth, nutrient utilization and amino acid digestibility of dairy calves fed milk replacers containing different amounts of protein in the preruminant period. Asian-Aust J Anim Sci. 2008; 21:1151-8. http://dx.doi.org/10.5713/ajas.2008.70562

13. McCormick ME, Webb KE Jr. Plasma free, erythrocyte free and plasma peptide amino acid exchange to calves in steady state and fasting metabolism. J Nutr. 1982;112:276-82.

14. Curthoys NP, Watford M. Regulation of glutaminase activity and glutamine metabolism. Annu Rev Nutr. 1995;15:133-59.

15. Haisch M, Fukagawa NK, Matthews DE. Oxidation of glutamine by the splanchnic bed in humans. Amer J Physiol. 2000;278:E593-602.

16. Wang W, Wu Z, Dai Z, Yang Y, Wang J, Wu G. Glycine metabolism in animals and humans: implications for nutrition and health. Amino Acids. 2013;45:463-77. doi:10.1007/s00726-013-1493-1.

17. Wu G, Knabe DA. Free and protein-bound amino acids in sow's colostrum and milk. J Nutr. 1994;124:415-24

18. Davis TA, Nguyen HV, Garciaa-Bravo R. Amino acid composition of human milk is not unique. J Nutr. 1994;124:1126-32.

19. Halfpenny AF, Rook JAF, Smith GH. Variations with energy nutrition in the concentrations of amino acids of the blood plasma in the dairy cow. $\mathrm{Br} J$ Nutr. 1969:23:547-57. http://dx.doi.org/10.1079/BJN19690063

20. Huntington GB. Net absorption of glucose and nitrogenous compounds by lactating Holstein cows. J Dairy Sci. 1984;67:1919-27. doi:10.3168/jds.S0022-0302(84)81525-8.

21. Stahel P, Cant JP, MacPherson JAR, Berends $H$, Steele MA. A mechanistic model of intermittent gastric emptying and glucose-insulin dynamics following a meal containing milk components. PLos One 2016; (in press) doi:10.1371/journal.pone.0156443.

22. Klinger S, Noci B, Müller K, Breves G. Intestinal glucose absorption in calves as affected by different carbohydrate sources. J Anim Physiol Anim Nutr. 2013;97:342-52. doi:10.1111/j.1439-0396.2012.01277.x.

23. Hammon HM, Sauter SN, Reist M, Zbinden Y, Philipona C, Morel C, Blum JW. Dexamethasone and colostrum feeding affect hepatic gluconeogenic enzymes differently in neonatal calves. J Anim Sci. 2003;81:3095-106.

24. Omidi-Mirzaei H, Khorvash M, Ghorbani GR, Moshiri B, Mirzaei M, Pezeshki A, Ghaffari MH. Effects of the step-up/step-down and stepdown milk feeding procedures on the performance, structural growth and blood metabolites of Holstein dairy calves. J Dairy Sci. 2015;98: 7975-81. doi:10.3168/jds.2014-9260.

25. Hammon HM, Schiessler G, Nussbaum A, Blum JW. Feed intake patterns, growth performance, and metabolic and endocrine traits in calves fed unlimited amounts of colostrum and milk by automate, starting in the neonatal period. J Dairy Sci. 2002;85:3352-62. doi:10.3168/jds.S0022-0302(02)74423-8.

26. Hüsier BR, Blum JW. Metabolic and endocrine changes in response to endotoxin administration with or without oral arginine supplementation. J Dairy Sci. 2002:85:1927-35. doi:10.3168/jds.S0022-0302(02)74269-0.

27. Kaufhold JN, Hammon HM, Bruckmaier RM, Breier BH, Blum JW. Postprandial metabolism and endocrine status in veal calves fed at different frequencies. J Dairy Sci. 2000:83:2480-90, doi:10.3168/jds.S0022-0302(00)75140-X.

28. Omole O, Brocks O, Nappert DR, Naylor JMG, Zello GA. High-performance liquid chromatographic assay of (6)-lactic acid and its enantiomers in calf serum. J Chromatogr. 1999;727:23-9. 
29. Caudarella R, Vescini F, Buffa A, Stefoni S. Citrate and mineral metabolism: kidney stones and bone disease. Front Biosci. 2003;1(8):s1084-106.

30. East DB. Biochemical pathways of creatine and creatine phosphate. University of Tennessee Honors Thesis Projects. http://trace.tennessee.edu/ cgi/viewcontent.cgi?article=1536\&context=utk_chanhonoproj.

31. Keaveney EM, Price RK, Hamill LL, Wallace JM, McNulty H, Ward M, Strain JJ, Ueland PM, Molloy AM, Piironen V, von Reding W, Shewry PR, Ward JL, Welch RW. Postprandial plasma betaine and other methyl donor-related responses after consumption of minimally processed wheat bran or wheat aleurone, or wheat aleurone incorporated into bread. Br J Nutr. 2015;113:445-53.

32. Houweling M, van der Drift SGA, Jorritsma RA, Tielens GM. Technical note: Quantification of plasma 1- and 3-methylhistidine in dairy cows by highperformance liquid chromatography- tandem mass spectrometry. J Dairy Sci. 2012:95:3125-30. doi:10.3168/jds.2011-4769.

33. Psychogios N, Hau DD, Peng J, Guo AC, Mandal R, Bouatra S, Sinelnikov I, Krishnamurthy R, Eisner R, Gautam B, Young N, Xia J, Knox C, Dong E, Huang P, Hollander Z, Pedersen TL, Smith SR, Bamforth F, Greiner R, McManus B, Newman JW, Goodfriend T, Wishart DS. The human serum metabolome. PLoS One. 2011;6:e16957. doi:10.1371/journal.pone.0016957.

34. Ametaj BN, Zebeli Q, Saleem F, Psychogios N, Lewis MJ, Dunn SM, Xia J, Wishart DS. Metabolomics reveals unhealthy alterations in rumen metabolism with increased proportion of cereal grain in the diet of dairy cows. Metabolomics. 2010;6:583-94. doi:10.1007/s11306-010-0227-6.

35. SAS Institute Inc. SAS/STAT 9.1 User's Guide. Cary: SAS Institute Inc; 2004.

\section{Submit your next manuscript to BioMed Central and we will help you at every step:}

- We accept pre-submission inquiries

- Our selector tool helps you to find the most relevant journal

- We provide round the clock customer support

- Convenient online submission

- Thorough peer review

- Inclusion in PubMed and all major indexing services

- Maximum visibility for your research

Submit your manuscript at www.biomedcentral.com/submit 